\title{
1. Introduction: transformational change in planning education pedagogy?
}

\author{
Andrea I. Frank and Artur da Rosa Pires
}

There may never have been a greater need for spatial planning than at the start of the 21st century with both urban and non-urban space transforming at unprecedented rates due to urbanization, sprawl and human-induced change to natural habitats. It is the task of planning and planners not only to guide communities, companies, and politicians on how to use and manage land based on scientific evidence, but also to build capacity to plan and shape places and spaces through creative vision into liveable, resilient, and sustainable communities. Planning is a relatively young and applied discipline, which has evolved and re-invented itself several times over. The field needs to adjust continuously; just like Engineering or Medicine, its practice is shaped by and reacts to external technological, demographic and societal factors. And, it is our belief that further deep and fundamental change, indeed a transformation, is needed to both how we plan and the requisite education and training so that future generations of planners are as best prepared to confront the contemporary challenges of the Anthropocene such as climate change, intensifying socio-economic inequalities, environmental pollution and decline, and growing resource scarcities. It will mean introducing new knowledge areas but also, more poignantly, new pedagogical approaches. These will be the focus of this volume.

Simply, the aim of this book is to foster and advance the dialogue on contemporary challenges to planning education, focusing particularly on pedagogies. It calls attention to ongoing and - arguably - transformational changes in spatial planning and its education provision by showcasing how educators from around the globe have begun to address emerging gaps in competencies with novel and innovative pedagogies and teaching.

\section{CONTEXT}

Education for urban and regional (spatial) planning began about a century ago when academics teaching at universities in Europe and the USA, in related disciplines such as civic engineering, architecture, landscape architecture, and 
geography, started to introduce courses covering urban issues. These courses, or modules in today's higher education terminology, included topics such as designing town extensions or doing civic surveys to diagnose and understand urban issues before developing 'treatments' and solutions. From such individual modules or courses gradually entire programmes of study emerged, first at postgraduate, and later also at undergraduate level, and nowadays provide education and training in the art and science of city building and design, and spatial planning to a growing cohort of planning professionals (Frank and Silver 2018).

In most countries, education for urban and spatial planning is delivered in higher education settings where it has been and remains closely linked to preparing students for professional practice. As professional profiles and curricula are linked to national contexts and institutional structures, the skills, knowledge and values to which graduates are socialized as part of their education relate, at least nominally, to guidelines produced by professional societies and bodies. This creates a valuable link between professional practice, and student employability (Frank 2020) - although the role of practitioners or professional bodies, in shaping or influencing curricula, varies and is not always clear cut (Poxon 2000). Over time, subject-specific pedagogies emerged and became accepted hallmarks of curricula shaped to instil planning relevant competencies, such as classes requiring project work (in some contexts called studios), various formats of work-based learning integral to the curriculum or extracurricular, group/team work and a range of activities to develop graphic, written and oral communication skills. Having developed from different disciplinary roots and learning traditions (Rodriguez-Bachiller 1988; Frank 2012), planning curricula have often focused on singular typologies of knowing and knowledge creation, leading to a heterogeneous professional profile globally.

Some common trajectories prevail, nevertheless. For example, we note how the focus of planning education changed, often in response to newly emerging needs and changing societal conditions (e.g., Brooks 1988; Hemmens 1988; Dalton 2001; Stiftel et al. 2009; Scholl 2012) and pedagogies and teaching approaches along with it (Lang 1983; Heumann and Wetmore 1984; Krueckeberg 1985). More specifically, these changes have included a move from a strong practice-oriented applied engineering and design tradition and relevant pedagogies like studios, fieldwork and internships to more theory, social science and economy with lectures and tutorials. In newer revisions of curricula, entrepreneurship and management training (Rodwin and Sanyal 2000; Guzzetta and Bollens 2003), with role play or simulations, as well as a re-establishment of studio and group projects (e.g., Neuman 2016) can be noted. Now, at the start of the 21 st century, it seems planning education curricula and pedagogies are due for another major shift in response to a collaborative and more recently transformative turn in planning. 
Over and over, planning has been identified as one of the professions vital to progressing the sustainability of cities and regions (Briassoulis 1999; Jepson 2001; UN Habitat 2009, 2016), replete with associated issues such as mitigating climate change, urban resiliency, inclusivity and so forth. However, progress towards developing more sustainable cities and places has been hampered by the difficulty of overcoming entrenched ways of doing things (Wolfram et al. 2019), and it is increasingly being argued that traditional approaches may no longer suffice (e.g., Rooij and Frank 2016; Albrechts et al. 2020). Collaborative and more recently transformative practices are being promoted which involve changes to the role and tasks of planning and its rationalities (Rodwin and Sanyal 2000) as well as the tools and the institutions involved in planning. For some, the transformative turn in planning means overcoming neoliberalist urbanism (e.g., Angotti 2020) with calls to adopt greater social, ecological and ethical responsibilities in the spatial planning and design fields (Salama 2015).

One should not underestimate the depth and breadth of these developments, which go beyond merely incorporating a new knowledge area. Frankly, it means that planners are expected to be able to address ever more complex and 'wicked' problems in challenging and fluid institutional settings. Transformative planning is frequently cutting across sectoral and territorial boundaries, engaging a variety of different actors through novel methods, while frequently acting outside the statutory framework. As champions of transitioning places away from unsustainable conditions, planners will need to be action-oriented, able to build alliances and overcome adversity. It requires creativity (Landry 2000; Albrechts 2005), not just in the traditional design sense, but employing creative thinking techniques more broadly (see De Bono 1992; Higgins and Reeves 2006). Success of future plans and the professionals behind them will depend on transparent and clear communication with a diversity of stakeholders including the general public. Peel (2000) forcefully argued that future planners are to be facilitators and coordinators of change change agents who empower others, co-create and co-shape urban districts, neighbourhoods and spatial development trajectories. There is also a need for more integration and merging of different traditions into single innovative and visionary programmes and developments (see Lamb and Vodicka, Chapter 2), with an openness to work with other fields and disciplines being one of the suggested areas of development. And while interdisciplinary literacies have been part of what planning education is to provide - in reality, pedagogies that foster interdisciplinary team working have been hard to implement in university settings upholding disciplinary silos and learning traditions. Moreover, risk-averse students and institutional efforts to harmonize and streamline educational experiences as a consequence of greater top-down quality assurance 
processes can stifle uptake of novel and experimental learning experiences where learning outcomes are potentially more unpredictable and variable.

At this point it is worth noting that, in a parallel development pedagogical research and educationalists are engaging in an unprecedented discussion about the challenges of education, and especially of higher education, in a globally changing world. They are suggesting, namely, that future cohorts of students will (a) have different expectations of their learning environment and how they prefer to learn, and (b) that educating for life in the 21 st century will require learners to develop different skills and dispositions to remain positive and action-oriented. Visser (2018) has argued, similarly, that the realities of global issues, such as climate change, loss of biodiversity, health endangering pollution and resource shortages which threaten, in fact, the existence of humanity itself, require a different learning landscape altogether. Drawing on Crutzen and Stoermer (2000, p. 18), who emphasized that "a world-wide accepted strategy leading to sustainability of ecosystems against human induced stresses will be one of the great future tasks of mankind, requiring intensive research efforts and wise application of the knowledge thus acquired" [emphasis added], Visser (2018, p. 6) suggests it is imperative to focus on emotional competencies (not merely knowledge) as prerequisite to profoundly change "our way of being in the world".

Some suggestions for developing students' transformational competencies necessary to effect transitional change can be gleaned from pedagogies identified as effective by the growing body of research into education for sustainable development (ESD). Studies suggest, for example, that experiential learning and action pedagogies (see e.g., Frisk and Larson 2011; Barth and Michelson 2013), as well as transformational learning spaces affording both physical space and "dedicated time for reflection, dialogue and action" (Moore 2005, p. 337), are valuable in ESD. It is also evident, that many transformational learning experiences occur in informal settings (Visser 2018). Both issues provide impetus when considering curriculum design and pedagogies.

The emerging perspectives on educational changes, and the inherent tensions with broader institutional constraints, are certainly of great relevance to planning education, which obviously unfolds precisely in such context. Nevertheless, the links between the two strands of debate, on wider educational changes and planning education per se, are essentially missing from much of the recent debates and are addressed only sporadically and in a rather fragmented way. There is certainly a need for a closer articulation between these two bodies of thought and this book aims to take a step forward in that direction by bringing together educationalists and planning educators to address and discuss change in the education of planners in contemporary society.

A third strand of thought exists that cannot be dissociated from the two previous ones and that certainly impinges on both of them. It is focused on the 
discussion about 'the University of the Future' and on how the university, and academia, will adapt to the political, technological, social and environmental drivers of change that will shape the world to come. Here the discussion spans from emerging efforts to counter the ever-increasing bureaucratization of the tertiary sector through to attempts to redesign the student learning experience as well as to redefine universities' missions as engaged universities (e.g., Goddard 2009; Barnett 2009, 2011, 2017). These discussions are, inter alia, opening up new avenues to develop collaborative and interactive curricula in which students can experience a meaningful action-oriented learning experience. Expectations are that students should be endowed with up-to-date scientific knowledge, but also basic and transversal skills, as well as with social and civic competencies, in order to engage more actively with communities and to foster the capacity to build innovative, inclusive and sustainable development transitions. Deep learning is facilitated by exposure to different kinds of real-world problems and processes of knowledge creation and development through design or scientific inquiry, which is in turn supported by intermittent reflections and theoretical discussions. All these themes add another layer of educational and pedagogical challenges to those mentioned earlier.

\section{APPROACH}

Given the above arguments and context, one of the questions that arises is how could and should a new learning landscape unfold and express itself specifically for the field of spatial planning? A second issue is how far the educational challenges, as well as personal development competencies, could be met with an adaptive evolution of current education traditions and practices or whether more fundamental and radical pedagogical changes would be needed?

Seeking to invoke a deeper and richer debate of these issues, we solicited case examples from planning educators featuring innovative and novel pedagogies in spatial planning, on the one hand, and, on the other, we invited prestigious educationalists to comment on (i) the broader changes that are likely to influence higher education in the years to come, in respect to educational and pedagogical approaches, and (ii) the implications or the challenges that the above trends will raise, in terms of educational approaches, to a specific field of practice that deals with changes in society, such as spatial planning. In order to connect the two types of contribution, a short description of the aims of the book, as well as a summary of each chapter, were made available to the educationalists.

In all, there are 13 case studies from a global set of planning educators spanning from Latin America to the Netherlands and Germany. This said, the collection does not claim to be comprehensive in any respect, as many excellent and noteworthy practices are not part of the volume. It simply would have 
been impractical. The focus here is on initial planning education, i.e. Bachelor and Master level programmes and to a minor extent continued professional development or advanced studies. We acknowledge that doctoral education for spatial planning will also require attention in future (see e.g., Kehm 2007; Internationales Doktoranden Kolleg 2016) but decided that this is beyond the scope of the present book. Also, as examples were drawn from presentations of the Association of European Schools of Planning (AESOP) congresses, there is a lack of cases from Asia, Africa and Australia/New Zealand.

The teaching case studies are written to enhance accessibility and sharing amongst the growing global community of planning educators. A broad definition of planning was applied to respect and indeed celebrate the diverse conceptions of planning in different national contexts. Thus, pedagogical initiatives are framed in a wider context and beyond the strict disciplinary borders of 'planning'. Although we refrained from using templates to impose format, we worked with the authors to ensure that case studies are written and structured in a manner to not only inspire but also facilitate adaptive use, reuse and evaluation through and by others. For that purpose, authors were asked to:

1. Provide a course description, content, and learning objectives;

2. Detail underlying concepts, rationale, and purpose, as well as links with contemporary planning challenges;

3. Offer a grounded critical analysis of the achievements so far; and

4. Identify main challenges and provide guidance and suggestions for implementation of similar initiatives.

Given the wide range of national contexts and higher education systems, readers should be aware that case studies use the terminology that is customary in the given context. For example, a teaching unit could be referred to as a module or course, while the entirety of a degree scheme might be labelled as a course or programme. For each case what is meant typically becomes clear as part of the context and we refrained from seeking a harmonization for the sake of it.

\section{THE STRUCTURE OF THE BOOK}

The book is divided into four parts bookended by this Introduction and a Conclusion. Part I provides an overview of general concepts dominating the pedagogical discourse in knowledge development and learning in and for higher education at the start of the 21 st century. Each of the following parts (II, III, IV) addresses a meta theme, in line with key challenges in contemporary planning education. The first theme is 'Teaching and learning in, for and with community', the second 'Developing new classroom-based competencies', 
and the third 'Further education and life-long capacity building'. While it is not necessary or intended that the book is read in sequence, it is recommended the reader engages with the educationalist commentary in conjunction with the case studies. It is also fruitful to study cases within each section together. In the following, details of the four central sections of the book and the relevant case contributions are introduced.

\section{Part I: Pedagogical Debates}

Part I introduces perspectives from the field of education. The two contributions enable a juxtaposition of trends and pedagogical developments in planning with those identified for postmodern education, pedagogy and higher education philosophy. In the chapter titled 'Education for 21st Century Urban and Spatial Planning: Critical Postmodern Pedagogies', Terry Lamb and Goran Vodicka provide an informed view of the growing "debate about how education can provide an appropriate preparation for life in the 21 st century" as well as the many educational reforms that have been introduced in many parts of the world since the turn of the millennium. They argue for a critical postmodern perspective, promoting "radically new pedagogies in order to respond to the complexities of a world in which it is impossible even to know what it means to 'know', when knowledge itself, as well as ways of knowing, are constantly shifting" and adding that such educational changes also need to take place in the field of urban planning. The authors endorse the view of "understanding pedagogy as a deeply civic, political, and moral practice" and produce proposals for new "urban planning and design practices and pedagogies", with due consideration to "the challenges and opportunities faced by those committed to innovative pedagogical interventions in higher education".

The next chapter, 'Planning Education and Planning the University: A Becoming-Symbiosis', by Ronald Barnett, provides a fascinating view of contemporary challenges to both planning practice and planning education through an insightful and creative exploration of the difficulties and opportunities associated with the fictional task of planning a university in the $21 \mathrm{st}$ century. Approaching the university as more than just a complex organization, recognizing the multiplicity of ways in which it is entangled with the wider world and how it faces competing internal and external interpretations of itself and its becoming, Barnett illustrates convincingly that "planning for such an assemblage as the contemporary university is bound to be thwarted with challenge". He argues that, faced with a multi-discursive world, planners and planning students need to be familiar not only with transdisciplinarity but with the more "ambitious" concept of "trans-spatiality", that "transcend[s] epistemological spaces and move[s] across ontological spaces". In other words, dealing with a multiplicity of discourses in any given planning situation will 
require students "to stretch themselves, stretch their being, into uncomfortable registers and modes of experience". The argument goes, then, "in such a conception of planning studies, students stand on a precipice and hurl themselves forward, not to their deaths but to their becoming". In this sense, "to involve students in the challenges of planning ... is at once a matter of curriculum and of pedagogy. The two cannot be separated: it is not a matter of choosing the what of the curriculum (contents) and then the how of the pedagogical approach. No. The two are interwoven." This is an absolutely remarkable and thought-provoking statement for reshaping planning education and pedagogical practices.

\section{Part II: Teaching and Learning in, for and with Communities}

Part II comprises five teaching cases, all of them dealing, in different and illuminating ways, with transdisciplinary issues, community involvement, co-creation and co-production of knowledge and the need to establish stronger links between science and society. Each case describes how educators have framed, facilitated, and managed the inclusion of stakeholders in teaching in particular modules/courses which are part of planning education programmes at different institutions. This reflects the trend in the sector to inclusive, communicative planning practices by introducing students to complex settings of urban politics, opening eyes to the diverse and often contradictory stakeholder interests and views in modern cities. Each chapter focuses on different issues.

A major innovation discussed in Chapter 4, 'Pedagogy Built on Working with Communities: A First Semester Core Course' by Ayse Yonder and colleagues, is a first-year module in a two-year Master's programme. This diverges from standard practices where students are as a norm gradually introduced to greater complexity and more difficult problems as they progress through their educational itinerary. The results are clearly positive and most students reveal a "true sense of enthusiastic learning". However, Yonder and colleagues are very attentive to the importance of adequate pedagogical support and conscious that studio pedagogy has changed over time, "shifting away from physical planning towards an emphasis on social science and research". And they also emphasize the importance of the institutional context, recognizing the Pratt Institute's legacy of studio pedagogy "not just for learning but creating knowledge" and an orientation "to address poverty and top-down government policies". As a consequence, they are sensitive to how the process impacts partner communities as well as to the tensions and frustrations that may occur among students, often associated with the "transformed subjectivities" deriving from students being confronted with residents that do not share their values. The result, in the words of one of the students, is that 
"the course is not only an introduction to planning but an opportunity to shape your values as an urban planner through practice and learning".

Chapter 5, 'Planning with the Community: Engaged Professional Education in an Ethno-Nationally Contested City', by Rachel Kallus, offers another example of community-based learning at Master level. Its focus is on how planning in an ethno-nationally contested city creates particular challenges and learning opportunities. The author explores the development, among students, of the sense of 'otherness', i.e., the capacity to learn about others, an experience that also leads students to learn about themselves, to face "the gap between their personal and professional identity [and to] undergo a process of identity formation". Such an experience can be as enriching as disturbing for the student, requiring "innovative engagement techniques" and an informed approach to reflexivity and to "critical pedagogy". Kallus highlights the educational challenges of enabling students to establish "a connection between society, knowledge, and context" and pinpoints the need to reflect about the dilemmas and responsibilities for educators of stimulating community engagement in situations where "the distinction between political orientation and political commitment is blurred" - namely, in the context of planning in contested places.

Chapter 6, 'Challenges in Education of Participatory Planning: Collaborating with Patients and Physicians to Plan Mental Health Facilities' by Elsa Vivant, offers a new approach of relating planning to society and community involvement in planning. Students are to consider the conditions of the (re)location of a new mental health care facility. In an insightful way, this project deepens appreciation of the concept of 'otherness' and the associated educational challenges. Working closely with mental health providers and patients, it offers students a new meaning to and understanding of otherness, confronting them in a rather blunt way with the socio-political and ethical implications of planning practice. Indeed, Vivant argues that the "by no means trivial" experience induces reflexivity amongst students, not only about the meaning and purpose of their work but also about their own beliefs, prejudices and values. She also addresses explicitly the challenges and responsibilities for educators, in what concerns students' well-being, since 'the emotional burdens and tensions involved in group projects can be exacerbated ... when working with a vulnerable population". Considering the rising concern of linking science with society this chapter offers a very original approach that may stimulate educational initiatives of linking planning with society in novel ways.

Chapter 7, 'Beyond the Classroom: New Skills through CommunityUniversity Outreach' by Camila D'Ottaviano and João Rovati, explores recent educational interventions at the universities of Porto Alegre and São Paulo. Community Outreach is a longstanding institutional mission of Brazilian universities and is part of the regular curriculum of all undergraduate courses. 
Although the interpretation and intensity of its application has varied significantly over time, the authors actively question "consolidated routines" and suggest outreach could pedagogically support "alternative planning practices". They argue that outreach should be seen as an "instrument to provide closer links between universities and society in order to address the deep social inequalities existent in Brazil", though they acknowledge some ambiguity and that academia tend to "value especially research and development of "pure knowledge' ... [and] when [academics] engage in 'practical' activities they usually do so to respond to 'market' demands". Assuming a different stance, the authors endorse Paulo Freire's pedagogical principles and see community outreach activities as a way to educate the qualified professional not only as the "technician" but also as the "humanized and socially committed individual". The learning-teaching methodology adopted, relying heavily on Freire's "pedagogy of autonomy", favours the blending of academic and popular knowledge and promotes sensitivity to the needs of the more fragile social groups as well as a "willingness to deliver", thereby stimulating a strong commitment to transform reality. The authors also address the institutional fragility of these activities, particularly the thinness of the available support and the limitations of the respective learning processes.

Chapter 8 by Gavan Rafferty and colleagues, 'Collaborative and Innovative Participatory Planning Pedagogies', is based on a research and curriculum enhancement project, involving students and educators from three different universities located respectively in Ireland, Italy, and Portugal. It was financially supported by the EU under the Erasmus + programme and included the purposeful and coordinated redesign of teaching modules, the engagement in community-based projects in each location and provided multi-contextual learning opportunities through 'blended' mobility study exchanges (for students, staff, local practitioners and civic actors). Allowing for participation in three real-life civic engagement experiences, the project aimed at preparing students to work in diverse cultural contexts, exploring different "transdisciplinary environments to share challenges, co-create knowledge and co-design solutions and actions". In addition to the specific pedagogical approach and learning, the possibilities of "co-designing multi-contextual learning opportunities across modules in multiple academic institutions" are particularly valuable and revealing.

\section{Part III: Developing New Classroom-Based Competencies}

Part III illustrates the development of new competencies (outside the community-university, participatory action realm). When considering the novelty of approaches, it is important to remember the contextuality of planning. In their own way, each of the cases shows educators challenging prevail- 
ing concepts and traditions and seeking to advance transdisciplinary thinking by perforating the boundaries between professions, teachers and learners.

Chapter 9 by Teresa Calix entitled 'Urban Design Studio as a Critical Learning Space within the Architecture Curriculum' is an account of changes in planning approaches and planning education over time. It is based on the evolving nature of an 'urban design studio', created in the late 1990s, in the final year of a first degree on Architecture. At the time, spatial planning in Portugal was not only experiencing significant changes but was also increasing its relevance (e.g., Rosa Pires 2018). The course was designed to provide "education for planning within an architecture programme [hoping] to contribute to the training of urbanists with a more comprehensive and broader view". Two decades after its creation, there is a need to accommodate changes in the approach to planning and in the characteristics and demands of Portuguese society. Calix shows how the course has been redesigned to incorporate interand trans-disciplinarity, to enhance communicative skills and to promote community engagement skills. The chapter illustrates a carefully nurtured process of introducing "changes in both content and pedagogical practices as a response to an evolving historical context".

Chapter 10 by Lukas Gilliard and colleagues, 'Addressing the Interplay of Design-Based Disciplines and Social Sciences in Urban Development Education', is also based in a design studio context, in this case of an interdisciplinary Master in 'Urbanism, Landscape and the City'. Starting from the premise that contemporary urbanism, and namely the relational conception of space, is questioning traditional planning concepts, such as 'cities as bounded territories', as well as conventional instruments of urban planning, the authors argue that new approaches are needed to guide the evolution of urban societies. Moreover, the argument goes, "the competencies for steering urban development are distributed among various disciplines ... [and] under these conditions, spatial planners will rarely work alone on projects". Having in mind that students (and professionals) tend to adopt ways of thinking that are specific to their disciplines, purposeful pedagogies and methodologies are then seen as absolutely necessary to facilitate working across disciplinary boundaries. The chapter describes a studio that aims not only "to provide students with knowledge on the key principles of 21 st century planning and development practice", but also to enable them to work collaboratively. This latter goal is achieved through the adoption of Trend Analysis as a methodological tool to effectively combine "the rationalist, scientific, empirical work of social scientists and the more subjective, creative work of architects and planners". The detailed description is punctuated by illuminating insights on the nature of contemporary development processes and the challenges they raise to traditional planning approaches. The failure to adequately address such challenges may lead, the authors argue, to the "political insignificance" of planning. 
The chapter by Marleen Buizer and Iulian Lata, 'Using Theatre and Performance for Greater Reflexivity in Planning and Design Education', illustrates the adoption of the same pedagogical approach in two different courses, one at undergraduate and the other at graduate level. In both cases, the aim is to promote reflexivity among students, stimulating them to reflect on their routines and roles as well as to question the rationale of adopting certain theoretical approaches in specific situations. This is facilitated through the adoption of theatre-based approaches as a heuristic tool to capture and understand the complexity, as well as the multiple and alternative interpretations of a given situation (or 'planning space'). The starting point is the need to prepare students "to enter an increasingly complex [networked] and dynamic world in which uncertainty, struggle and conflict are more common than predictability, consensus and straightforward collaboration". In this context, planners are not anymore seen as "gatekeepers to knowledge, those able to understand, provide the evidence and develop interventions accordingly". Rather, a crucial capacity is their "critical engagement" in a given situation, able to capture the subjective, contested, and political dimensions of a given situation and to deliver "transformative planning practices". Reflexivity becomes a key tenet of "context-specific technical rationality" and the theatre-based approach to support-learning processes is shown as an effective tool for this objective. This is a truly inspiring chapter about the pedagogical routes to sensitizing students and planners to their "responsibility for the places and communities in which they operate" - and a timely word of caution in relation to the uncritical ways in which transdisciplinary and participatory methodologies are being adopted.

Chapter 12 by Andreas Brück and Angela Million, 'Mikroakademie: Peer Learning to Enrich the Curriculum and Enhance Participation and Self-Reflection', presents an approach that deliberately aims at reaching "beyond the scope of standard teaching". On one hand, it is seen as a way to address "a very practical need to broaden the scope of the curriculum" in order to meet the content requirements of contemporary planning. On the other hand, it is used to endow students with skills and abilities, like the capacity of autonomous, life-long learning that is seen as fundamental for coping with 21 st century challenges. The Mikroakademie consists of interactive sessions where peer-to-peer learning is stimulated, and students are invited to assume the role of educators. The concept was developed initially to respond to the growing need of planners to communicate ideas with multiple audiences by providing students with opportunities to learn a wide variety of communication and representation techniques "within a studio atmosphere". There are important lessons to be learned from how the approach overcame institutional constraints. Over time, as the programme became established, the innovative teaching-learning processes helped to position teaching as learning, as a part of 
individuals' instinctive behaviour, growth and development while engendering also a "transformation of planning education from the bottom-up".

\section{Part IV: Further Education and Life-Long Capacity Building}

Part IV showcases another important aspect of transformation of future planning education given the need to strengthening pathways into the planning profession (e.g., Commonwealth Secretariat 2011) and for continued professional development and life-long learning identified both by professional societies and governments. The four case studies offer not only alternative and non-traditional pathways of becoming a planner and progressing one's competencies in spatial planning but also concepts for short interventionist activities as a means to provide innovative educational experiences in spatial planning.

Chapter 13 by Adam Sheppard, 'Online, but Not Isolated: Addressing a Key Challenge of Digital Distance Learning', reflects on the recent revision to a longstanding distance learning Master's in Planning, which moved from blended learning (online with residential weeks) to fully online delivery. The contribution offers interesting insights into overcoming student isolation a characteristic of online settings, which could impede learning, the student experience as well as impoverish and hamper the acquisition of soft skills such as collaboration and communication that are vital for the planning field. The difficulty of delivering such competencies remotely has been used in arguments against moving planning degrees to online learning in the past. Remarkable is the close cooperation with students that guided the redesign of the programme architecture. By creating an elaborate hierarchy of different types of virtual spaces and interaction opportunities from formal classrooms and associated activities to casual interactions in coffee shops, the learning environment mirrors (to some degree) the manifold social interactions experienced on university campuses. Akin to the material campus, control over spaces differs, and interactions are variably instigated by the educators or by students or in some cases by both.

The second case in this section likewise provides a programme view. Chapter 14, 'A Problem-Based and Process-Oriented Curriculum in Continuing Education' by Anita Grams, elaborates on a part-time postgraduate degree at the ETH Zurich, specifically designed to upskill experienced and already practising planners through training in particular advanced methodologies and interdisciplinary team working. In fact, a prerequisite of admission to the programme is a prior degree in a spatially related discipline and several years of work experience. The focus throughout the programme is on developing competencies in defining problems and finding solutions for complex real-life, urban, and regional planning tasks in projects at different scales. The study mode is a mix of face-to-face and remote team working. The programme rep- 
resents an interesting model of advanced higher education where professional practice is informing and at the same time is informed through theory and study experiences in a complex Kolbian cycle of learning (Kolb 1984).

Chapter 15, 'Professional Training for Social Responsibility: Fundamentals and Practice of a Residency Programme in Architecture and Urbanism' by Maria L. Refinetti Martins and Paula Custódio de Oliveira, discusses a collaborative post-degree training programme (aka residency) of one year delivered jointly between the University of São Paulo's Faculty of Architecture and Urbanism and the city of São Paulo. The aim of the residency programme is to train early career planning professionals. It is like the previous case a structured continued education experience. Nevertheless, the interpretation and context of planning is starkly different. Students attend tailor-made classes at university and work in parallel on projects such as developing district plans. By combining 'academic' and 'professional' activities, participants are enabled to conduct broader research while also gaining an understanding of the constraints of public management. Through the residency programme, actors (city administration, universities, and professionals) collaboratively provide important technical assets and construct knowledge which increases the probability of project and plan implementation. The residency programme facilitates engagement of students and university staff in addressing prevailing social issues in the nation's urban areas and as such offers a new type of pedagogical approach embodying Barnett's (2017) engaged university.

Chapter 16, 'A Student Workshop on Tactical Urbanism: One Day to Change the 100th Year Neighbourhood?' by Duygu Cihanger Ribeiro, presents and critically reviews a short extracurricular teaching intervention in form of a four-day event. Expanding on the standardized approaches in Turkish planning curricula that tend to focus on strong technical and design skills conceiving city plans and urban level projects, this event introduces an alternative approach to planning and city making, known as 'tactical urbanism'. This approach promotes the use of temporary, small-scale, action-based interventions that typically involve local users to effect bottom-up change and transformation. Over a few days, participants get to know a place, and in discussion with inhabitants become familiar with issues. Interventions are conceived, created, and implemented in an ad hoc fashion showcasing and testing potential solutions, as well as developing visions for change and creating discussion points. The case features an enriching learning opportunity for students from different universities. However, a transfer to a continued professional development activity for practitioners can easily be imagined. 


\section{TOWARD A NEW LEARNING LANDSCAPE FOR EDUCATION IN PLANNING}

To recapitulate, then, in this human-dominated era, at the start of the $21 \mathrm{st}$ century, there is an urgent need to get better at, i.e. learn, how to interact constructively and ethically with a complex world in flux (Visser 2018). This requires, first, a more inclusive view of learning, a broader view of what counts as valid knowledge (Rooij and Frank 2016) and an ability and disposition to "adapt readily to rapidly changing environments" (Lebler 2007, pp. 206-7). Second, it requires new ways of learning (pedagogies) and learning environments. It may require new worldviews potentially triggered by experiential and/or transformative pedagogies (Mezirow 2009). There is broad consensus amongst education specialists that learning requires and at the same time results from exchange, open-minded interaction and dialogue with much being gained through inter- and trans-disciplinary exchanges. This applies not only for the learner but the educator who is a learner at the same time.

Scholarly meetings and professional congresses of planners and planning educators have traditionally provided forums of exchanges and dialogue on how to develop the field's pedagogies to best suit professional practice needs albeit largely without interdisciplinary exposure. Over the last two decades or so a considerable surge in engagements with pedagogical innovation geared towards improving knowledge and skills acquisition for contemporary planning challenges can be noticed. The diversity of initiatives, with rationalized and clearly defined purpose, creativity and the commitment by planning educators has grown significantly. However, as research in substantive areas is prioritized in many academic settings, the discourse rarely moves beyond congress debates and only occasionally into a journal. This means the debate is far from reaching the in-depth level sought by both the presenters and the audience.

This book, thus, seeks to leverage and create space for this deeper debate by beginning to conceptually interrogate educational philosophy and theory in the spatial planning context. We hope that such a forum will stir the imagination of fellow planning educators to continue to work with other disciplines, and particularly educationalists, to develop appropriate environments for learning and personal development that will prepare planning graduates and practitioners to cope with and shape ethically the unknown futures (Barnett 2004) of our urban and non-urban environments.

Transforming planning education curricula and pedagogies will be an ongoing process. The case studies in this volume illustrate a range of contemporary trends. Still, the picture is partial and incomplete. Other noteworthy examples have recently emerged with planners drawing creatively on methods 
from other subject areas, such as ethnography. These variably expand the repertoire of research and data collection methods, tap into different fields of knowledge by trying to understand a place through biographical accounts or transversal walks over a week or longer, conducting immersive observations and casually but purposefully talking to locals. Another pedagogy that is more applied and action-oriented, the living labs (Evans et al. 2015), is inspired by science experiments in the broadest sense.

The manuscript for this book was completed as a majority of the world's population was asked to drastically change their lifestyle and behaviour from one day to the next in response to combating a global health pandemic triggered by the COVID-19 virus. The associated strict social distancing measures have stopped abruptly fieldwork, research, collaboration, and joint activities - temporarily at least. In time we believe this will be overcome - but how co-design and action-learning may be transformed to be more flexible and resilient will need to be contemplated so as not to entirely revert to theoretical debate and project work that is disconnected to the many realities on the ground and outside the campus walls. Ironically, socially responsible engagement is perhaps more than ever needed in such disruptive times. A positive of every crisis is that it inevitably sparks creativity and we will reflect on some ideas for hybrid (online and face-to-face) adaptations in our final chapter.

\section{REFERENCES}

Angotti, T. (ed.) (2020) Transformative Planning: Radical Alternatives to Neoliberal Urbanism. Chicago: University of Chicago Press/Black Rose Books.

Albrechts, L. (2005) Creativity as a driver for change. Planning Theory 4(3): 247-269.

Albrechts, L., Brabanente, A. and Monno, V. (2020) Practicing transformative planning: The territory-landscape plan as a catalyst for change. City, Territory and Architecture 7(1). https://doi.org/10.1186/s40410-019-0111-2.

Barnett, R. (2004) Learning for an unknown future. Higher Education Research and Development 23(3): 247-260.

Barnett, R. (2009) Knowing and becoming in the higher education curriculum. Studies in Higher Education 34(4): 429-440.

Barnett, R. (2011) The coming of the ecological university. Oxford Review of Education 37(4): 439-455.

Barnett, R. (2017) Constructing the university: Towards a social philosophy of higher education. Educational Philosophy and Theory 49(1): 78-88.

Barth, M. and Michelsen, G. (2013) Learning for change: An educational contribution to sustainability science. Sustainability Science 8(1): 103-119.

Briassoulis, H. (1999) Who plans whose sustainability? Alternative roles for planners. Journal of Environmental Planning and Management 42(6): 889-902.

Brooks, M. (1988) Four critical junctures in the history of the urban planning profession: An exercise in hindsight. Journal of American Planning Association 54: 241-248. 
Commonwealth Secretariat (2011) Commonwealth Capacity Building for Planning: Review of Planning Education across the Commonwealth. London and Edinburgh: UCL Development Planning Unit and Commonwealth Association of Planners.

Crutzen, P. and Stoermer, E. (2000) The 'Anthropocene'. Global Change Newsletter 41: $17-18$.

Dalton, L. (2001) Weaving the fabric of planning as education. Journal of Planning Education and Research 20(4): 423-436.

De Bono, E. (1992) Serious Creativity: Using the Power of Lateral Thinking to Create New Ideas. New York: Harper Business.

Evans, J., Jones, R., Karvonen, A. Millard, L. and Wendler, J. (2015) Living labs and co-production: University campuses as platforms for sustainability science. Current Opinions in Environmental Sustainability 16: 1-6.

Frank, A. I. (2012) Time to think planning (education): From marginal interface to central opportunity space? In L. Bertolini (ed.), 'Interface: Time to Think, Time to Act'. Special Issue of Planning Theory \& Practice 13(3): 465-490.

Frank, A. I. (2020) Education and demonstration of professional competence. In N. Green Leigh, S. P. French, S. Guhathakurta and B. Stiftel (eds.), The Routledge International Handbook of Planning Education (pp. 12-28). New York: Routledge.

Frank, A. I. and Silver, C. (2018) Urban Planning Education: Beginning, Global Movement and Future Prospects. Chams: Springer.

Frisk, E. and Larson, K. L. (2011) Educating for sustainability: Competencies \& practices for transformative action. Journal of Sustainability Education [Online]. http:// www.susted.com/wordpress/content/educating-for-sustainability-competencies -practices-for-transformative-action_2011_03/ [Accessed 29 May 2020].

Goddard, J. (2009) Reinventing the Civic University. London: NESTA.

Guzzetta, J. A. and Bollens, S. A. (2003) Urban planners' skills and competencies: Are we different from other professions? Does context matter? Do we evolve? Journal of Planning Education and Research 23: 96-106.

Hemmens, G. C. (1988) Thirty years of planning education. Journal of Planning Education and Research 7(2): 85-91.

Heumann, L. F. and Wetmore, L. B. (1984) A partial history of planning workshops: The experience of ten schools from 1955 to 1984. Journal of Planning Education and Research 4(2): 120-130.

Higgins, M. and Reeves, D. (2006) Creative thinking in planning: How do we climb outside the box? The Town Planning Review 77(2): 221-244.

Internationales Doktoranden Kolleg (2016) Urbane Transformations-landschaften/ Urban Landscape Transformations. Berlin: Jovis.

Jepson, Jr., E. J. (2001) Sustainability and planning: Diverse concepts and close associations. Journal of Planning Literature 15(4): 499-510.

Kehm, B. M. (2007) Quo vadis doctoral education? New European approaches in the context of global changes. European Journal of Education 42(3): 307-319.

Kolb, D. A. (1984) Experiential Learning: Experience as the Source of Learning and Development (Vol. 1). Englewood Cliffs, NJ: Prentice Hall.

Krueckeberg, D. (1985) The tuition of American planning. Town Planning Review 56(4): 421-441.

Landry, C. (2000) The Creative City: A Toolkit for Urban Innovators. London: Earthscan.

Lang, J. (1983) Teaching planning to city planning students: An argument for the studio/workshop approach. Journal of Planning Education and Research 2(2): 122-129. 
Lebler, D. (2007) Student-as-master? Reflection on a learning innovation in population music pedagogy. International Journal of Music Education 25: 205-220.

Mezirow, J. (2009) Transformative learning theory. In J. Mezirow and E. W. Taylor (eds.), Transformative Learning in Practice: Insights from Community, Workplace, and Higher Education (pp. 18-32). San Francisco, CA: Jossey-Bass.

Moore, J. (2005) Seven recommendations for creating sustainability education at the university level: A guide for change agents. International Journal of Sustainability in Higher Education 6(4): 326-339.

Neuman, M. (2016) Teaching collaborative and interdisciplinary service-based urban design and planning studios. Journal of Urban Design 21(5): 596-615.

Peel, D. (2000) The teacher and town planner as facilitator. Innovations in Education and Training International 37(4): 372-380.

Poxon, J. (2000) Shaping the planning profession of the future: The role of planning education. Environment and Planning B 28: 563-580.

Rodriguez-Bachiller, A. (1988) Town Planning Education: An International Survey. Aldershot: Avebury.

Rodwin, L. and Sanyal, B. (eds.) (2000) The Profession of City Planning: Changes, Images, and Challenges 1950-2000. New Brunswick, NJ: Transaction Publishers.

Rooij, R. and Frank, A. I. (2016) Educating spatial planners for the age of cocreation: The need to risk community, science and practice involvement in planning programmes and curricula. Planning Practice and Research 31(5): 473-485.

Rosa Pires, A. (2018) Breaking the ties with the master plan: Spatial strategic plans in Portugal. In L. Albrechts, J. Alden and A. Rosa Pires (eds.), Changing Institutional Landscape of Planning (pp. 181-208). New York: Routledge (first published 2001 by Ashgate Publishing).

Salama, A. M. (2015) Spatial Design Education: New Directions for Pedagogy in Architecture and Beyond. London and New York: Routledge.

Scholl, B. (ed.) (2012) HESP - Higher Education in Spatial Planning: Positions and Reflections. Zürich: Vdf Hochschulverlag.

Stiftel, B. et al. (2009) Planning education. In UN Habitat (United National Human Settlements Programme), Planning Sustainable Cities (Chapter 10). London: Earthscan.

UN Habitat (2009) Planning Sustainable Cities. London: Earthscan.

UN Habitat (2016) Urbanization and Development: Emergent Future. World Cities Report 2016. Nairobi: United Nations Human Settlements Programme.

Visser, J. (2018) The Anthropocene: A different learning landscape for a different world. Lecture delivered at the Universitas Nusa Cendana in Kupang, Indonesia 10 October.

Wolfram, M., Borgstrom, S. and Farrelly, M. (2019) Urban transformative capacity: From concept to practice, Ambio 48: 437-448. 